\title{
Propiedades del primer sistema de teledetección hiperespectral chileno
}

\author{
Marco A. Peña
}

La teledetección es la disciplina científica que deriva información de un elemento mediante la detección y análisis de su energía radiada. Durante los últimos años, esta disciplina ha experimentado un notorio avance impulsado por el creciente progreso de las técnicas de espectroscopia, aparejado al mejoramiento y abaratamiento de sus tecnologías de medición (sensores remotos). Como resultado de lo anterior, las imágenes de la superficie terrestre, adquiridas desde satélites o aviones, han llegado a ser productos de teledetección rutinariamente empleados por numerosos y diversos organismos públicos y privados en todo el mundo (Lucas et al., 2004; Liang, 2008).

El desarrollo de la teledetección en Chile queda de manifiesto con la próxima puesta en órbita del primer sensor satelital multiespectral (Sistema Satelital de Observación Terrestre, SSOT) y la actual implementación del primer sensor aéreo hiperespectral (Sistema Prototipo de Observación Remota Hiperespectral, SPORH). Sin embargo, las capacidades de extracción de información que brindan las imágenes adquiridas por estos y otros tipos de sensores remotos pueden llegar a diferir notoriamente, por lo que la elección del producto más adecuado para una aplicación de interés exige el conocimiento de sus propiedades técnicas. En principio, resulta útil diferenciar los productos generados mediante teledetección pasiva de aquellos generados mediante teledetección activa. Esta última se ocupa de detectar y analizar la señal de radiación que retorna de un objeto al que se le dirige un pulso de energía o rayo. Instrumen-

\footnotetext{
1 Centro de Estudio de Recursos Naturales Oterra, Universidad Mayor (Chile). E-mail: marco.pena@ umayor.cl
}

tos propios de este tipo de teledetección son el radar, el sonar y el lidar. La teledetección pasiva en tanto, detecta y analiza la radiación solar reflejada o emitida por un objeto, que al comprender regiones espectrales entre el visible y el infrarrojo (desde los 400 a los $2.500 \mathrm{~nm}$ ) es Ilamada teledetección óptica. Los sensores o cámaras multiespectrales e hiperespectrales son ejemplos de instrumentos empleados por este tipo de teledetección ( $\mathrm{Li}$ llesand et al., 2004; Aronoff, 2005; Eastman, 2006).

No toda la teledetección genera imágenes del objeto observado. Así por ejemplo, mediante espectrometría de campo la energía radiada por un objeto es almacenada como un dato espacialmente adimensional. Es la teledetección de tipo pictórica (más precisamente conocida como espectroscopia de imagen) la que representa la radiación proveniente de un objeto en la forma de una imagen; ya sea panorámica o planimétrica (Lillesand et al., 2004; Lucas et al., 2004). La utilidad que pueden brindar las imágenes ópticas para una aplicación dada depende de sus resoluciones espacial, espectral, radiométrica y temporal. Frecuentemente, la resolución espacial es la propiedad que recibe mayor atención al momento de elegir una imagen, pues determina el nivel de detalle con que puede ser visualizada la superficie retratada en ella, que se define por el tamaño de lado del píxel (celda regular mínima de información en un archivo de datos raster). No obstante, la verdadera importancia de la resolución espacial radica en la posibilidad de extraer datos espectralmente puros desde una imagen. En efecto, si la superficie de un píxel está compuesta en su totalidad por el objeto de interés, entonces la radiación medida en él será "pura", pues corresponderá a un único objeto (Lefsky y Cohen, 2003; Asner, 2003; Lucas et al., 2004; Borengasser et al., 2008). 
La resolución espectral es la propiedad más influyente en la capacidad de extraer información de una imagen, por cuanto determina el nivel de detalle con que puede ser detectado el comportamiento espectral de la superficie retratada en ella, que se define por el número de bandas (intervalos de longitudes de onda espectral que componen a una imagen). Al aumentar la cantidad de bandas dentro de un rango espectral dado, aumenta la probabilidad de detectar señales espectrales asociadas a propiedades fisicoquímicas específicas de un elemento, pues dicho rango es medido en intervalos más estrechos. Así, aunque una imagen cuente con una excelente resolución espacial, si se compone de pocas bandas será difícil, si no imposible, extraer información espectral lo suficientemente precisa como para caracterizar y discriminar numerosos objetos (Chang, 2003; Borengasser et al., 2008).

La resolución radiométrica se define como el nivel de cuantificación de radiación en las bandas de la imagen. Mientras más valores de radiación son medidos en las bandas, más probabilidades existen de distinguir diferencias entre las señales que produce un objeto a lo largo de ellas. Así, aunque una imagen cuente con una excelente resolución espectral, si los niveles de radiación de sus bandas son groseramente medidos será difícil identificar señales de reflexión o absorción lo suficientemente precisas como para caracterizar y discriminar numerosos objetos (Aronoff, 2005).

Otra propiedad que caracteriza a las imágenes ópticas es la altura a la que son capturadas. Un sensor remoto puede situarse a nivel del suelo (sensor de campo), en diferentes capas atmosféricas (sensor aéreo) o en el espacio (sensor espacial). A medida que aumenta la altura de sobrevuelo de la plataforma que transporta al sensor, aumenta el ancho de la atmósfera que debe recorrer la radiación detectada desde la superficie, lo que a su vez aumenta el ruido o radiación extraña añadida por efecto de esparcimiento de los aerosoles atmosféricos. De esta forma, antes de analizar cuantitativamente los datos contenidos en una imagen satelital o aérea adquirida a gran altura (miles de metros sobre la superficie) es indispensable aplicar procedimientos de corrección atmosférica que eliminen o minimicen la influencia de la atmósfera en el flujo ascendente de radiación (Lillesand et al., 2004; Aronoff, 2005). Finalmente, la programación de adquisición de estas imágenes puede llegar a ser muy variable. Mientras hay sensores satelitales que adquieren imágenes de un mismo punto geográfico a intervalos de tiempo regulares (que pueden ir desde un par de días a varias semanas), otros adquieren imágenes solo por requerimiento, lo que supone solicitar y programar su captura, proceso que suele tardar meses. Aunque los sensores aéreos pueden ser más flexibles en este punto, existen ciertos fenómenos que ocurren en ventanas de tiempo tan estrechas que no pueden ser apropiadamente cubiertos mediante el uso de estas plataformas. Por otro lado, tanto los sensores aéreos como satelitales se ven limitados por la nubosidad y luminosidad atmosférica. Más aún, en el caso del sensor aéreo se suman restricciones de vuelo por turbulencia atmosférica (Lefsky y Cohen, 2003).

Durante el segundo semestre del año 2008 el Centro de Estudio de Recursos Naturales Oterra de la Universidad Mayor comenzó la ejecución del proyecto "Implementación de un Sistema Prototipo de Observación Remota Hiperespectral para la Caracterización y Análisis de los Recursos Silvoagropecuarios", una iniciativa nueva en Chile, que mediante la investigación básica y aplicada busca generar nuevos y mejores niveles de información para la planificación y gestión de los recursos agrícolas y forestales. El proyecto contempla diseñar e implementar un sistema de adquisición de imágenes hiperespectrales e hiperespaciales de la superficie terrestre, de alta flexibilidad temporal en la captura de datos y bajo costo de operación. Los componentes principales del SPORH son: un espectrómetro de imagen (escáner de alta resolución espectral y espacial), un sistema de posicionamiento geográfico directo (unidad de medida inercial y sistema de posicionamiento global integrados) y una aeronave ultraliviana (aunque a escalas regionales el proyecto contempla el uso de plataformas de mayor envergadura, tales como un Twin Otter). El proyecto busca mejorar la calidad de información que hoy da sustento a la toma de decisiones relacionadas con los recursos vegetales, mediante la puesta en el mercado de productos (por ejemplo, imágenes y cartografía temática) que respondan oportuna- 
mente a necesidades propias de la agricultura de precisión, incorporen superficies que por su menor tamaño no han podido acceder a tecnologías de teledetección y proporcionen conocimiento con una razonable relación precio-calidad. La iniciativa ha sido financiada por la Universidad Mayor, la Corporación de Fomento de la Producción (CORFO), la empresa de ingeniería ambiental Infraeco (grupo Aretech) y la empresa de turismo y diseño de aviones ultralivianos Ultrasport.

El escáner (Hyspex VNIR-1600@) cuenta con 1.600 detectores de voltaje arreglados linealmente dentro de un campo de visión instantáneo de $17^{\circ}$, lo que lo faculta para obtener imágenes con una resolución espacial submétrica (hiperespaciales) aun sobrevolando un área a miles de kilómetros sobre su superficie (Cuadro $N^{\circ} 1$ ). Por otro lado, el instrumento posee una sensibilidad espectral que abarca todas las regiones visibles y la región del infrarrojo cercano del espectro electromagnético (desde los 400 hasta los $1.000 \mathrm{~nm}$ ). Este rango espectral es muestreado en intervalos contiguos de $3,7 \mathrm{~nm}$, lo que resulta en la obtención de imágenes con una resolución espectral de 160 bandas (hiperespectrales). Cada banda cuantifica la radiación reflejada en una escala de 65.536 valores, en unidades de $\mathrm{W} / \mathrm{m}^{2} \times \mathrm{nm} \times \mathrm{sr}$, lo que equivale a una resolución radiométrica de 16 bits. El Cuadro $N^{\circ} 2$ compara las principales propiedades técnicas del SPORH con otros sistemas de teledetección espacial óptica.
Cuadro $N^{\circ} 1$

Resolución espacial y ancho de la imagen a distintas altitudes de vuelo

\begin{tabular}{|c|c|c|}
\hline $\begin{array}{c}\text { Altitud de } \\
\text { vuelo }(\mathrm{m})\end{array}$ & $\begin{array}{c}\text { Tamaño de } \\
\text { píxel }(\mathrm{cm})\end{array}$ & $\begin{array}{c}\text { Ancho de } \\
\text { barrido }(\mathrm{m})\end{array}$ \\
\hline 100 & 3,7 & 59 \\
500 & 18,5 & 296 \\
1.000 & 37 & 592 \\
1.500 & 56 & 888 \\
2.000 & 74 & 1.184 \\
\hline
\end{tabular}

Fuente: Elaboración propia.

La aeronave ultraliviana (Flightstar-IISC(C) cuenta con una generación de energía en velocidad crucero $(150 \mathrm{w})$ que permite la operación del escáner y sus aparejos sin necesidad de baterías, una velocidad mínima $(72 \mathrm{~km} / \mathrm{h})$ que permite la adquisición de imágenes de alta calidad radiométrica y espectralmente íntegras a bajas altitudes (por ejemplo, 100-200 metros sobre la superficie), una capacidad de carga $(220 \mathrm{k})$ que permite transportar los equipos y hasta dos tripulantes y una autonomía de vuelo $(3,5$ h) que permite la adquisición de imágenes alrededor del momento de mayor intensidad de radiación solar y mejor iluminación del terreno (cenit solar). La disponibilidad de más de 350 aeródromos a nivel nacional, así como el consumo de combustible de 97 octanos, hace que esta ae-

Cuadro $\mathrm{N}^{\circ} 2$

Comparación de las propiedades técnicas de varios sistemas de teledetección espacial óptica

\begin{tabular}{|l|c|c|c|c|c|}
\hline Sistema & $\begin{array}{c}\text { Capacidad } \\
\text { espectral }\end{array}$ & $\begin{array}{c}\text { Número } \\
\text { de bandas } \\
\text { visible }\end{array}$ & $\begin{array}{c}\text { Número de } \\
\text { bandas infrarrojo } \\
\text { cercano }\end{array}$ & $\begin{array}{c}\text { Tamañode } \\
\text { píxel (m) }\end{array}$ & $\begin{array}{c}\text { Tiempo de solicitud } \\
\text { y programación de } \\
\text { adquisición }\end{array}$ \\
\hline Quickbird & multiespectral & 3 & 1 & 2,4 & $>1$ mes \\
Terra - ASTER & multiespectral & 2 & 1 & 15 & $>2$ mes \\
Landsat - ETM+ & multiespectral & 3 & 1 & 30 & Revisita c/16 días \\
EO1 - Hyperion & hiperespectral & 44 & 46 & 30 & $>4$ meses \\
SPORH & hiperespectral & 108 & 52 & $<0,5$ & $\begin{array}{c}\text { Según } \\
\text { requerimiento }\end{array}$ \\
\hline
\end{tabular}

Fuente: Elaboración propia. 
ronave pueda moverse con facilidad por todo el país, pudiendo incluso despegar y aterrizar desde cualquier terreno plano improvisado. Más aún, los materiales ligeros que la componen (aluminio, fibra de vidrio, poliéster) y su simple construcción, posibilitan desarmarla y moverla por tierra mediante un carro acoplado a un vehículo motorizado convencional.

Las propiedades técnicas reseñadas hacen que el SPORH posea un gran potencial para aplicaciones vinculadas al manejo y monitoreo de los recursos agrícolas y forestales. Cabe mencionar que las imágenes ópticas son relevantes para estudiar la vegetación porque la mayoría de la radiación solar está comprendida entre las regiones espectrales visible e infrarrojo de onda corta. Esto implica que las plantas han adaptado su estructura y fisiología para interactuar con la radiación del rango espectral óptico (fotosíntesis), de manera que conociendo su comportamiento espectral en ese rango podemos derivar información relevante de ellas (Lefsky y Cohen, 2003; Borengasser et al., 2008). Al respecto, el SPORH cuenta con propiedades que permiten una caracterización y análisis de la condición vegetal en profundidad gracias a su alta resolución espectral, que es capaz de proveer comportamientos espectrales detallados de la vegetación de interés y con ello permitir la detección de señales sutiles vinculadas a la presencia de varios de sus componentes (nutrientes, pigmentos). Esto no es posible mediante el uso de imágenes multiespectrales, que por su escaso número y amplio intervalo de bandas impiden o limitan la detección de muchos componentes vegetales (Treitz y Howarth, 1999; Lucas et al., 2004; Blackburn 2006; Govender et al., 2007). Asimismo, la alta resolución espacial del sistema favorece la detección de radiación proveniente desde plantas pequeñas, permitiendo aplicaciones en una amplia variedad de cultivos a escalas locales. Resoluciones espaciales inferiores a medio metro aún no pueden ser ofrecidas por sistemas de teledetección espacial. Finalmente, en términos temporales el SPORH ofrece una alta flexibilidad para cubrir áreas de interés, por cuanto puede ser puesto en operación de forma lo suficientemente rápida como para adquirir imágenes durante las ventanas de tiempo requeridas por el usuario. Esta propiedad pasa a ser clave en el ámbito vegetacional, en que muchos problemas relacionados a la fenología y estrés de la planta requieren soluciones "justo a tiempo" (estrés nutricional, brotes de plagas). Los actuales sistemas de teledetección espacial y aérea presentan dificultades para responder rápidamente a requerimientos de imágenes, debido al tiempo que toma solicitarlas y programar las rutas orbitales y líneas de vuelo, respectivamente.

\section{Referencias bibliográficas}

ARONOFF, S. Remote Sensing for GIS Managers. California: ESRI Press, 2005.

ASNER, G.; HICKE, J. \& LOBELL, D. Perpixel analysis of forest structure: vegetation indices, spectral mixture analysis and canopy reflectance modeling. En: WULDER, M. A. \& FRANKLIN S. E. Remote Sensing of Forest Environment, Concepts and Case Studies. Massachussets: Kluwer Academic, 2003, p. 209-254.

BLACKBURN, G. A. Hyperspectral remote sensing of plant pigments. Journal of Experimental Botany, 2006, vol. 58, № 4, p. 855-867.

BORENGASSER, M.; HUNGATE, W. S. \& WATKINS, R. Hyperspectral Remote Sensing, Principles and Applications. Florida: CRC Press, 2008.

CHANG, C. Hyperspectral Imaging, Techniques for Spectral Detection and Classification. $1^{\text {st }}$ ed. New York: Kluwer Academic, 2003.

EASTMAN, R. IDRISI Andes Guide to GIS and Image Processing. Maryland: Clark University, 2006.

GOVENDER, M.; CHETTY, K. \& BULCOCK, $\mathrm{H}$. A review of hyperspectral remote sensing and its application in vegetation and water resource studies. Water $S$ A, 2007, vol. $33,^{\circ} 2$, p. 145-152.

LEFSKY, M. A. \& COHEN, W. B. Selection of remotely sensed data. In: WULDER, M. A. \& FRANKLIN, S. E. Remote Sensing of Forest Environment, Concepts and Case Studies. Massachussets: Kluwer Academic, 2003, p. 13-46. 
LIANG, S. Recent advances in land remote sensing: an overview. In: LIANG, S. Advances in Land Remote Sensing, System Modeling, Inversion and Application. Maryland: Springer, 2008, p. 1-6.

LILLESAND, T. M.; KIEFER, R. W. \& CHIPMAN, J. W. Remote Sensing and Image Interpretation. New York: Wiley, 2004.
LUCAS, R.; ROWLANDS, A.; NIEMANN, O. \& MERTON, R. Hyperspectral sensors and applications. In: VARSHNEY, P. K. \& ARORA, M. K. Advanced Image Processing Techniques for Remotely Sensed Hyperspectral Data. Berlin: Spriger, 2004, p. 11-49.

TREITZ, P. M. \& HOWARTH P. J. Hyperspectral remote sensing for estimating biophysical parameters of forest ecosystems. Progress in Physical Geography, 1999, vol. 23, No 3, p. 359-390. 